\title{
THE OCCURRENCE OF SYNCHRONIZED JUMPING CROWD AT SPORTS STADIUMS
}

\author{
MARTIN VERNER \\ Czech Technical University in Prague, Faculty of Civil Engineering, Thákurova 7, 16629 Prague 6, Czech \\ Republic \\ correspondence: martin.verner@fsv.cvut.cz
}

\begin{abstract}
Since the age of the Rome Empire, people have been going for fun at the stadiums. Today, important reasons for visiting the stadium are sport games or cultural performances. The text is about occurrence of specific types of behaviour during sport games. The experiment was realized at four different sports stadiums and during three kinds of sports. The worst case of loads for the grandstand is the synchronized jumping of a crowd. This is type of behaviour, which can cause over limit vibration, visitors discomfort on the tribune, in the extreme case collapse of the grandstand. In any country today, the standards or references or math models are not for application of dynamic load to grandstand. Only the British standards are making recommendation how the designer should work with dynamic loads.
\end{abstract}

KEYWORDS: Grandstands, synchronized jumping, football, ice-hockey, biathlon.

\section{INTRODUCTION}

The jumping (especially the synchronized jumping of all rows of fans synchronized) is the main element of fans supporting their lovely team at stadiums. In 2010, the grandstands were shaking at football stadium in the Nuremberg, Germany. Behaviour of spectators caused "huge" vibration of grandstands during match of Bundesliga between 1. FC Nuremberg and FC Eintracht Frankfurt. The tribune survived the rising level of vibrations 1 .

The main question of the text is: What is the frequency of the occurrence of synchronized jumping crowd at sports stadiums in the Czech Republic.

The research took place in the years 2013-2017. There was monitored the fans behaviour during the different sports matches and the acceleration of the grandstand structure was measured. The experiments were realized at the Football stadium - Prague Letná, Ice-hockey stadium - Pilsen, Football stadium - Prague Eden and Biathlon stadium - New Town in Moravia. Example types of construction figure 3, 4,

\section{TyPES OF FANS BEHAVIOUR}

During the experiment, nine types of fans behaviour was recorded: Walking and running, Jumping, Bouncing/Bobbing/Jouncing, Swaying, Handclapping, Static state, Goal scoring and Mexican wave. The response to the grandstand vibrations are the higest during jumping. The type of behaviour -jumping-is divided to four subtypes [2].

Jumping of the $1^{\text {st }}$ type: The fans are jumping alone - independently. The synchronization is realized only by drum. The drum is usually placed between fans named "Ultras".
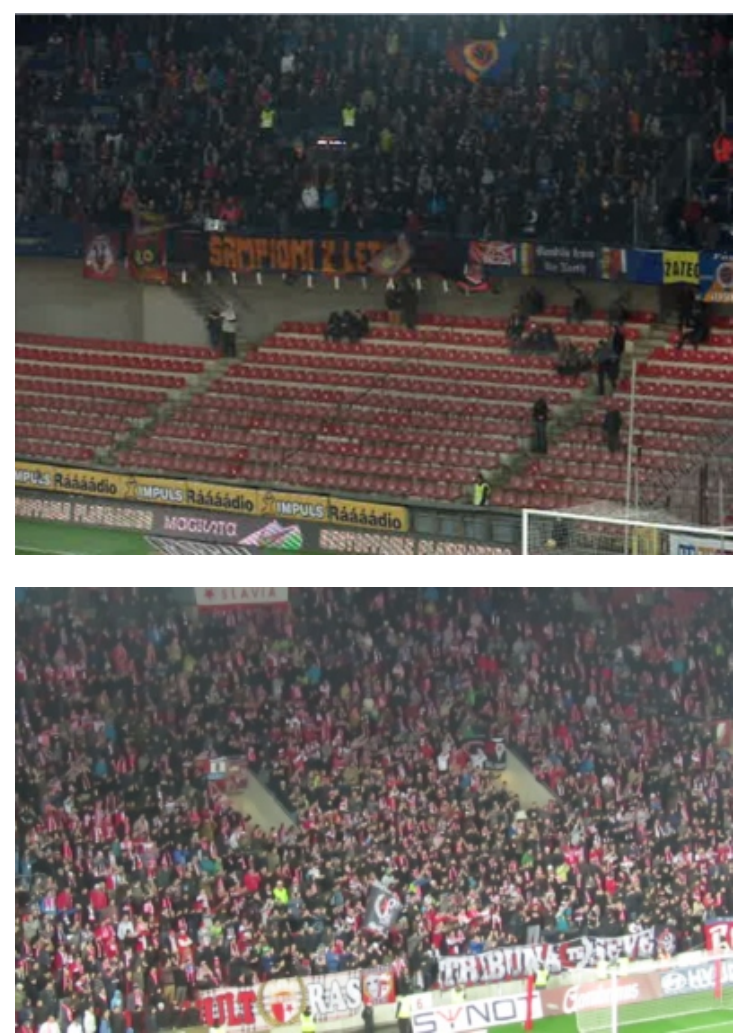

Figure 1. Photo of fans: Football stadium - Prague Letna(upper) [2], Football stadium - Prague, Eden (lower) 3]. 

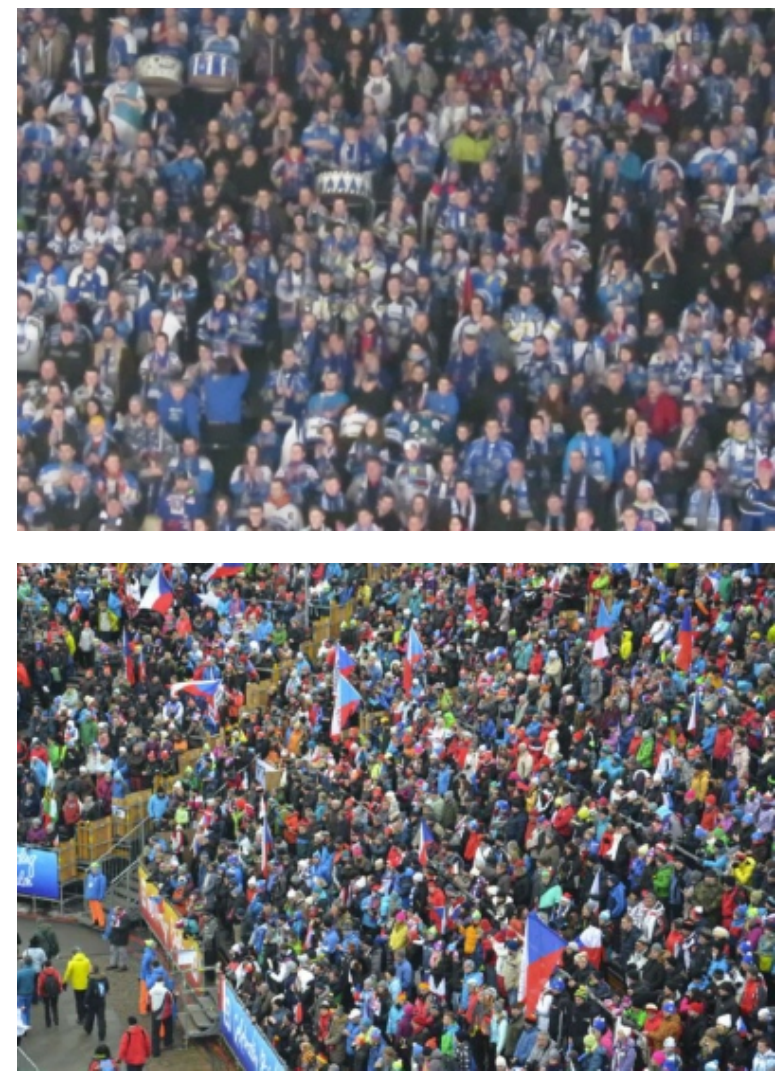

Figure 2. Photo of fans: Ice-hockey stadium - Pilsen (upper) 4, Biathlon stadium - New Town in Moravia (lower) [5].

Jumping of the $2^{\text {nd }}$ and the $3^{\text {rd }}$ types: The fans are grabbing around shoulders and they are jumping all rows (vertically (type 2) or horizontally (type $3)$ ). The synchronization is the fastest of all types of behaviours and vibrations on the grandstand are maximal.

Jumping of the $4^{\text {th }}$ type: The type is called: Sit and Jump. Spectators are sitting then they jump up when the Ultras leader order to do it. The text focuses on the 2. and the 3. types of jumping. These types of fans behaviours caused the maximal vibration of the grandstand.

\section{REALIZED EXPERIMENTS}

\subsection{Experiment New TOWn in Moravia}

The fans of behaviour (Figure 2 influenced by the instability of the assembled grandstands in the New Town in Moravia. The jumping was prohibited because the organizers were afraid of high vibrations of the grandstands during this type of behaviour. Interdiction of the jumping was respected during the race.

\subsection{Experiment Prague Letna}

The monitoring of fans was realized at football stadium Prague Letna during the spring part of the Czech Football League (2014/2015). The stadium
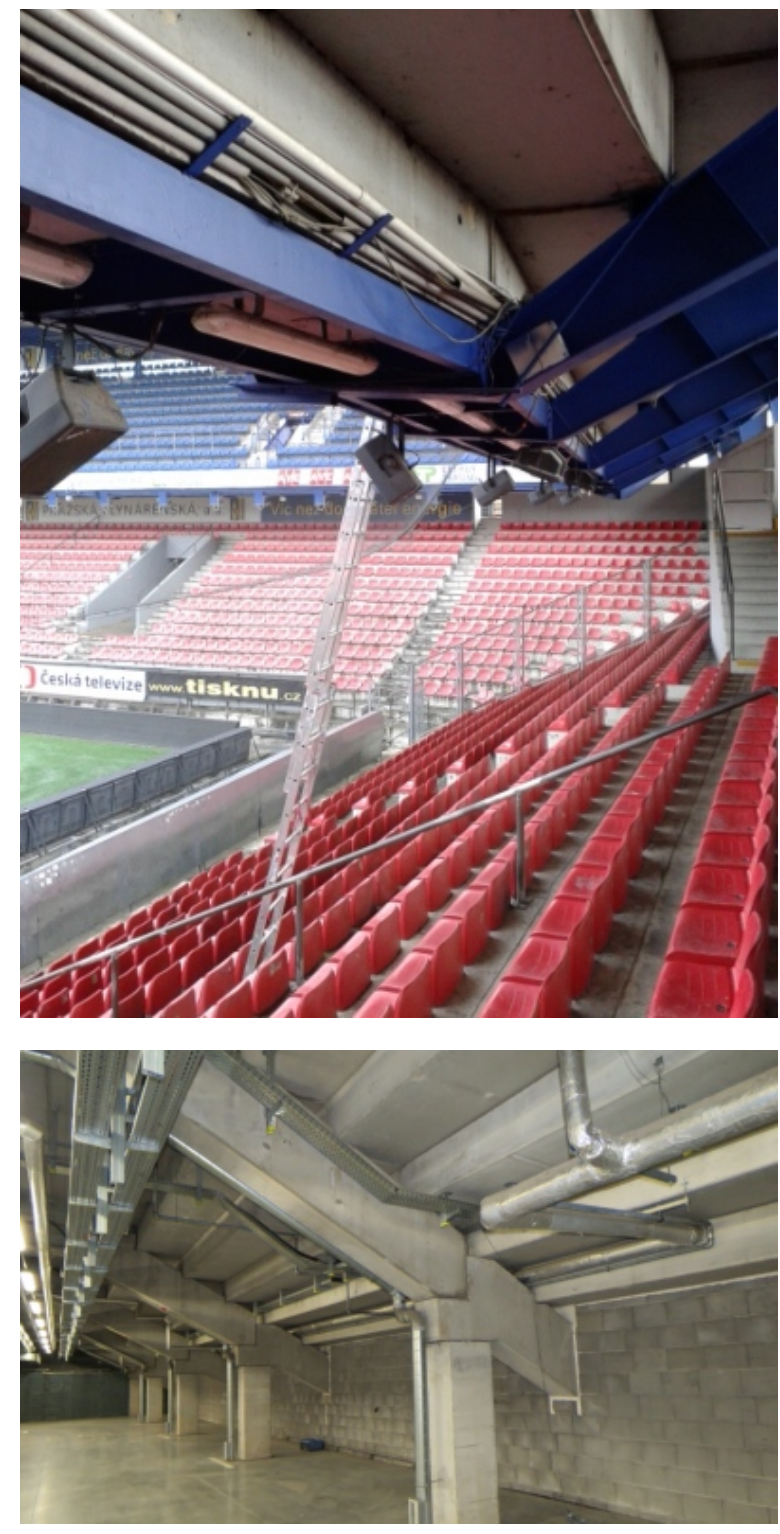

Figure 3. Construction of monitored grandstands: Football stadium - Prague Letna(upper) 2, Football stadium - Prague Eden (lower) [3].

is the home stadium of the team AC Sparta Praha. The team has one of the faithful and dangerous fans (Figure 1) in the Czech Republic.

AC Sparta Praha reached around second place of football table. The attendance of fans was falling down during the end of the football season. Sparta finished at the second place of the football season. In the table 1, there are the described football matches and the occurrence of the synchronized jumping of the $2^{\text {nd }}$ and the $3^{\text {rd }}$ type (Figuge 7 ).

\subsection{Experiment Pilsen}

The experiment was realized at the Ice-hockey stadium - Pilsen during all the Czech Ice-hockey League (2015/2016). Long-term monitoring was cocerned to spectators' behavivour during ice-hockey matches as for the football matches. Specifically, the monitoring 

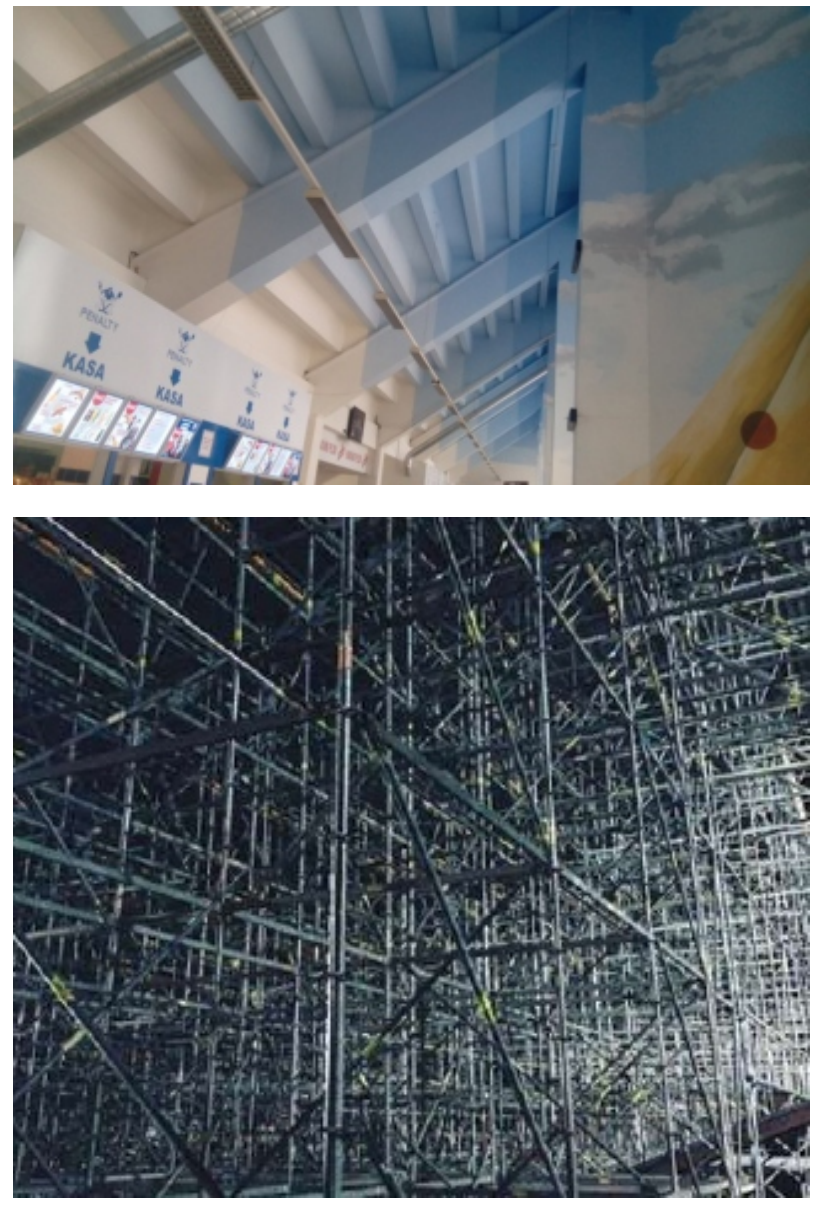

Figure 4. Construction of monitored grandstands: Ice-hockey stadium - Pilsen (upper) [5], Biathlon stadium - New Town in Moravia (lower) [4].

was focused on fans (Figure 2) supporting team HC Skoda Plzen.

HC Skoda Plzen reached upper part of the icehockey table. The team finished at the fourth place of the ice-hockey regular season. After regular season, Pilsen team played ice-hockey play-off and it finished at the semi-final. The experiment recorded twenty games of the regular season of possible twenty-six and six games of play-off.

The synchronized jumping of all rows did not occur when the camera was recording during the experiment. This behaviour is not a part of the ice-hockey fans style to support their team. This is a marginal issue of cheering.

In 2016, the Winter Classic Game (outdoor game) was played in Brno. The match is a part of ice-hockey season between HC Kometa Brno and HC Škoda Pilsen. Assembled grandstands (Figure 5), similar to the one in New Town in Moraqvia, where build for this match. As the grandstands had similar construction, jumping was also prohibbited, but this ban was broken. The vibrations of grandstands could be felt, Tribunes were very uncomfortable.

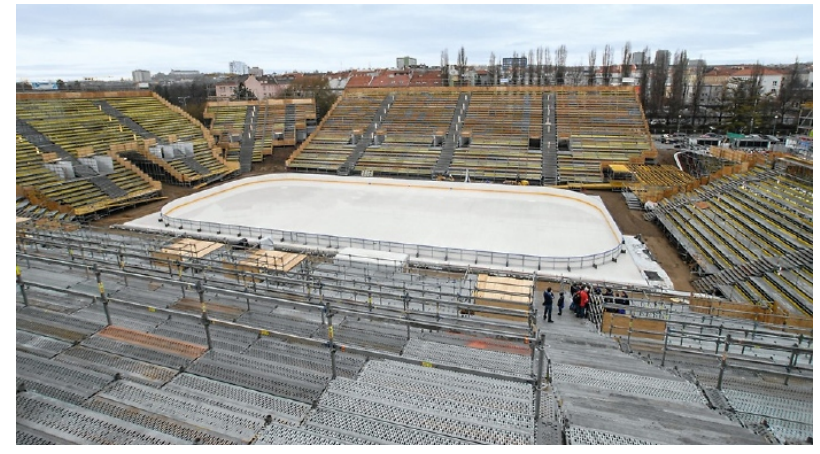

Figure 5. Construction of grandstands in Brno [6].

\subsection{Experiment Prague Eden}

The monitoring of fans (Figure 1) was realized at the football stadium Prague Eden again during the spring part of the Czech Football League (2015/2016). The stadium is the home stadium of the team SK Slavie Praha. The team is like AC Sparta Praha, it has one of the faithful and dangerous fans in the Czech Republic.

SK Slavie Praha reached around the fifth place of the football table. Attendance of fans was not falling down with the end football season. In the table 2, there are the described football matches and the occurrence of the synchronized jumping of the $2^{\text {nd }}$ (Figure 6) and the $3^{\text {rd }}$ type.

\section{Conclusion}

The results of the experiments show the big differences between fans of behaviours at football stadium and at the other stadiums. Behaviours of crowds were affected by the instructions from the organizers during the biathlon races. The synchronized jumping was not observed at any ice-hockey game during the experiment in Pilsen. Only the author of text was a direct witness of the synchronized jumping crowd during the Winter Classic Game in Brno. Fans realized the synchronized jumping of all rows at least once at every football match during the experiment. Difference of behaviour between stadium Prague Letna and stadium Prague Eden was the different used types of jumping. In the stadium Prague Eden, fans were preferring jumping all rows - horizontally, on the other hand the spectators were jumping all rows vertically in the stadium Prague Letna. The results of the experiment are the fundamentals for the next evolution.

It describes the behaviour of the fans, the gained data will be determined further in the other research: how many people do it and how the attendance influences the level of the vibration of grandstands.

\section{ACKNOWLEDGEMENTS}

This paper has been supported by the Czech Science Foundation project No. GA15-15728S and Faculty of Civil Engineering, Czech Technical University in Prague (SGS project No. SGS16/201/OHK1/3T/11). 


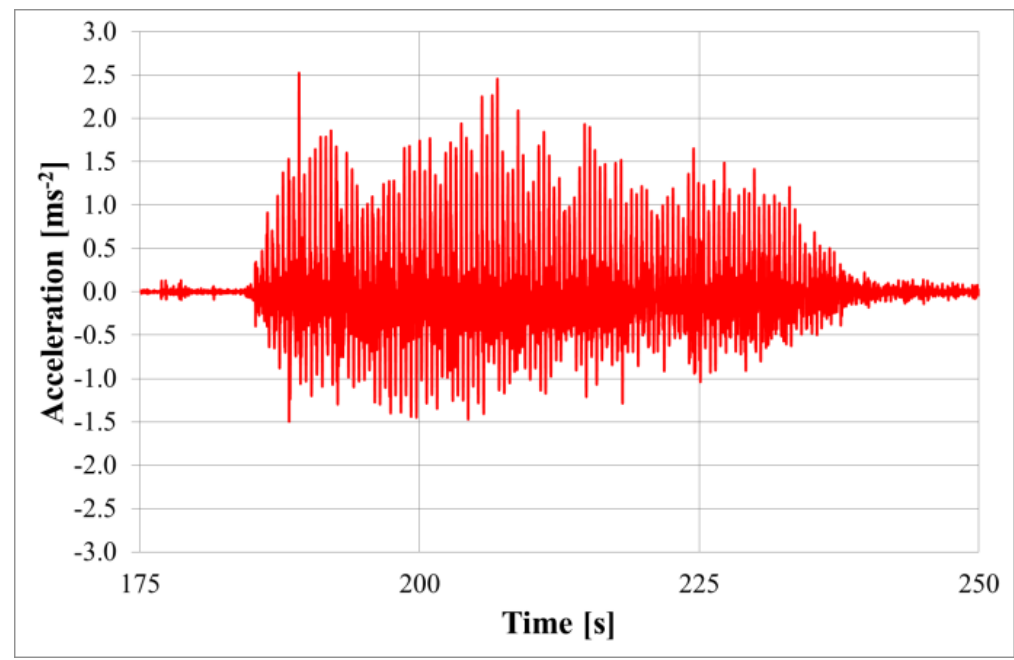

Figure 6. The sample of the grandstand vertical vibration (Praha Eden) - jumping rows - vertically $[3]$.



FiguRE 7. The sample of the grandstand horizontal vibration (Praha Letna) - jumping rows - horizontally [3].

\begin{tabular}{|c|c|c|c|c|}
\hline \multirow{2}{*}{ Date } & \multirow{2}{*}{ Matchweek } & \multirow{2}{*}{ Rival } & \multicolumn{2}{|c|}{ Types of Jumping } \\
\hline & & & Jumping of the $2^{\text {nd }}$ & Jumping of the $3^{\text {rd }}$ \\
\hline March 8, 2015 & 19. & FK Dukla Praha & $2 \times$ & $2 \times$ \\
\hline March 21, 2015 & 21. & FK Teplice & $1 \times$ & $1 \times$ \\
\hline April 26, 2015 & 25. & FC Zbrojovka Brno & $1 \times$ & - \\
\hline May 15, 2015 & 28. & 1. FC Slovacko & $2 \times$ & $1 \times$ \\
\hline May 30, 2015 & 30. & FC Bohemians Praha & $1 \times$ & - \\
\hline
\end{tabular}

TABLE 1. Table of occurrence of synchronized jumping crowd during the match - AC Sparta Praha.

\begin{tabular}{ccccc}
\hline \multirow{2}{*}{ Date } & Matchweek & Rival & \multicolumn{2}{c}{ Types of Jumping } \\
\cline { 3 - 4 } & & & Jumping of the 2 ${ }^{\text {nd }}$ & Jumping of the $3^{\text {rd }}$ \\
\hline February 28, 2016 & 19. & FC Banik Ostrava & $1 \times$ & $1 \times$ \\
March 11, 2016 & 21. & FC Fastav Zlin & - & $1 \times$ \\
April 23, 2016 & 26. & FK Teplice & - & $1 \times$ \\
May 8, 2016 & 28. & 1. FC Slovacko & - & $1 \times$ \\
\hline
\end{tabular}

TABLE 2. Table of occurrence of synchronized jumping crowd during the match - SK Slavie Praha. 


\section{REFERENCES}

[1] M. Verner. Real crowd behavior on the grandstands. 4th Conference Nano \&S Macro Mechanics 4(6):215-220, 2013.

[2] M. Verner, T. Plachy, M. Polák. An experiment focused on fans behaviour and induced grandstand vibrations during a football match. Trans Tech Publications Offices (4):75-78, 2016.

[3] M. Polák, T. Plachy, M. Verner. A comparison of spectators induced grandstand vibrations and fans behavior during two ice hockey games between the same teams in the regular season and in the playoffs. 3rd
International Conference on Structural and Physical Aspects of Construction Engineering 3(4), 2016.

[4] J. Hubka. Dynamic analysis of grandstand. Master's Thesis. 2017.

[5] M. Verner. Behaviour of fans during the football match. Trans Tech Publications 102(4):77-80, 2016.

[6] PERI. Winter classic lužánky, brno. https://www . peri.cz/projekty/kulturni-a-sportovni-akce/ winter-classic-luzanky.htmll 